\title{
PRE-PRINT
}

This is a copy of a paper accepted for publication by the journal:

Architectural Science Review 2012

\section{Exploring the Influence of Housing Design and Occupant Environmental Attitudes on Energy and Water Usage}

\author{
Ben O'Callaghan ${ }^{1}$ \\ Heather J. Green ${ }^{2}$ \\ Richard A. Hyde ${ }^{1}$ \\ David Wadley ${ }^{3}$ \\ Anir Upadhyay ${ }^{1}$ \\ ${ }^{1}$ Faculty of Architecture, Design and Planning \\ The University of Sydney, NSW, Australia \\ ${ }^{2}$ School of Applied Psychology \& Behavioural Basis of Health Program, Griffith Health \\ Institute, Griffith University, Gold Coast, QLD, Australia \\ ${ }^{3}$ School of Geography, Planning and Environmental Management \\ The University of Queensland, QLD, Australia \\ ben.ocallaghan@sydney.edu.au \\ Tel. +61419409887 \\ Running Head: SUSTAINABLE HOUSING, ATTITUDES, RESOURCE USAGE \\ Key words: energy efficiency, sustainable design, resource usage, utility consumption, \\ occupant attitudes
}




\begin{abstract}
Sustainable housing is intended to achieve a lower impact on the environment but it is unclear is to what extent occupants and their behaviour are a determinant in realising this goal. In this paper, occupant attitudes toward the environment are used as an indicator of behaviour whilst resource usage is taken as an indicator for the environment. A study of occupants of sustainable and conventional housing in the same climate zone is engaged to examine this question. The results show that the former use $75 \%$ less energy compared with those of conventional houses of the same age. More positive attitudes to environmental conservation correlated with lower energy use, but were not found to be a statistically significant predictor of energy use when analysed with other variables. Hence, we argue that sustainable housing characteristics and associated technologies have a much higher weighting relative to occupant attitudinal factors. The data also suggest that the sustainable design of a detached house is associated with approximately double the reduction in energy consumption, compared with the influence of pro-environmental attitudes. Hence, sustainable attributes are a significant indicator in determining resource usage. The implications of these results bear strongly on the debate over the influence of behavioural factors compared with technological factors in the drive to greater energy efficiency.
\end{abstract}

Keywords: energy consumption, energy efficiency, environmental attitude, resource usage, solar passive design, sustainable design, utility consumption, sustainable development, water consumption 


\section{Introduction}

The intention of sustainable compared with conventional housing is to integrate technology and passive design principles, thereby reducing environmental impacts through technical efficiency. Yet, the attitudes and behaviours of the occupants would appear to play a part in the overall use of key resources like water and energy. Despite prior research, the balance between design and attitude remains inadequately understood. The objective of this article is to contribute more evidence to what has become a problematic issue. The research involves several tasks. Initially existing studies on sustainable housing, policy and occupant attitudes were examined. Next we frame sustainability not only as facet of the environment but also as a facet of quality of life to capture the social determinants found in the housing research context. Finally another set of tasks concerns the construction of a field trial capable of probing the research objective, presentation and interpretation of the data, and discussion of the results.

This paper reports on the research in five sections. The first is a background and account of prior research organised to expose key variables in the relevant context. It includes consideration of the sustainability and quality of life nexus. The second describes the formulation and conduct of the empirical project, which is set in Queensland, Australia. It is followed by a statement of results, leading to an inclusive discussion of issues and findings. Finally, conclusions make clear the contribution of the article to the problem earmarked for research.

\section{Background and Literature Review}

\section{Sustainable Housing Design and Occupant Attitudes}

A primary consideration in this project is that, although building a sustainable residence might assist in reducing water and energy consumption through passive measures, consumption efficiencies can also be impacted by the behaviour of the occupants. Thus, 
potential impacts of bothhousing design and relevant occupant attitudes, values and behaviours need quantifying to focus policy and funding on public and private measures that will make the most difference. This is an important issue in light of the International Panel on Climate Change's (IPCC, 2007, p. 389) statement that:

"While occupant behaviour, culture and consumer choice and use of technologies are also major determinants of energy use in buildings and play a fundamental role in determining $\mathrm{CO}_{2}$ emissions (high agreement, limited evidence), the potential reduction through non-technological options is rarely assessed and the potential leverage of policies over these is poorly understood"

The question is thus the relative influence of these key determinants. To address this gap, the current research examines both technological (design) and non-technological (attitudinal) influences on utility consumption. Hereby, it is also necessary to take into account other key variables known to be associated with utility consumption. Australian Government data have shown that the size of a dwelling, number of occupants, and construction type are significant influences (Australian Bureau of Statistics, 2008). These associations indicate that increased dwelling size, more occupants, and separate houses are all related to higher utility use. The study of energy use amongst 14 sub-divisions of Sydney, by Manfred, Christopher \& Barney (2004), confirmed that domestic energy use correlated with number of occupants as well as with income and age. The enquiries by Troy, Holloway, and Randolph (2005) and Grafton (2009), amongst others, have identified several significant influences on water consumption, including age of occupants and socioeconomic status.

Consistent with prominent conceptualisations in the behavioural research literature, an "attitude" is defined in the present research as a positive or negative feeling about taking a specific action (Fishbein \& Ajzen, 1972). Also congruent with relevant research and theory is the assumption that attitudes regarding actions tend to be correlated with the relevant 
behaviours, but the correspondence between attitudes and behaviours is less than exact (Fishbein \& Ajzen, 1972). Both attitudes and behaviour are most frequently measured by selfreport. Similar to attitudes, self-reported behaviour also has a less than perfect association with observed behaviour. In understanding influences on environmentally favourable behaviours, both attitudes and behaviour need to be considered. Here, the focus is on attitudes rather than behavioural measures. However, an advantage of this approach compared with much of the research on environmental attitudes is its ability to incorporate utility consumption reflective of the occupants' behaviour.

A number of studies has demonstrated that pro-environmental attitudes are associated with increased ecological behaviour (Kaiser, Wölfing, \& Fuhler, 1999; Martimportugués, Canto, García, \& Hidalgo, 2002). In 2006, the instrument used in the present study, the Environmental Attitudes Inventory, demonstrated that higher Preservation attitudes predicted self-reported ecological behaviour, whereas Utilisation attitudes were associated with values favouring economic liberalism (Milfont \& Duckitt, 2006). Meta-analysis has also previously demonstrated a significant correlation between environmental attitudes and behaviour (Hines, Hungerforda, \& Tomerab, 1987).

Contrasting data from a Norwegian study showed no statistically significant difference in annual private energy consumption between respondents with positive environmental attitudes and others (Holden \& Linnerud, 2010). Similar lack of association is found in two previous studies by the same first author (Holden, 2004a, 2004b). Holden and Linnerud proposed at least three mechanisms which influence whether households are able to behave in an environmentally friendly way: a desire to project an environmentally friendly image, a desire to self-indulge, and a sense of powerlessness. In their opinion, information campaigns to raise people's environmental awareness have very little effect on the level of energy use in the house. Holden's findings suggest, however, that domains other than domestic energy 
consumption offer far more opportunities to influence attitudes and encourage environmentally friendly solutions. Contrasting results from several major surveys conducted by Norway's National Institute for Consumer Research demonstrate clear links between respondents' level of environmental awareness and behaviour such as sorting waste for recovery, taking environmental considerations into account when shopping, and choosing ecological food products (Lavik, 1997). More research is needed both in housing and other sectors to gain a clearer picture of associations between environmental attitudes and resource usage.

The current project examines variables which influence energy and water consumption in a residential setting. For this study, 'sustainable development' is defined as 'development which meets the needs of the present without compromising the ability of future generations to meet their own needs' (United Nations, 1986) and "sustainable house design" is understood as dwelling design planned to be more socially, environmentally and economically sustainable (Queensland Government, 2010).

\section{Quality of Life as an Indicator of Sustainability}

A further consideration is that overall resource consumption and environmental impact are linked to quality of life (Hyde \& Rostvik, 2008). Recent definitions capture alternative perspectives such as "carbon neutral", or "zero-carbon", housing. There are many examples of quality of life (QoL) studies worldwide, but few have combined biophysical and attitudinal factors in the analysis. Wandersman \& Hallman (1993, p. 681) suggested that 'to respond effectively to environmental problems, policy makers must know as much about the social, emotional and behavioural impacts of environmental threats as they do about the biological effects'. Models of sustainable development (Mawhinney, 2002) suggest that QoL can be maintained or improved through the integration of social, economic and environmental needs. Unfortunately, there are few tools available for the planning and design of precincts to 
improve sustainability and reduce environmental impacts of a development (Hyde et al., 2005). However, 'green' rating tools such as the United States Leadership in Energy and Environmental Design (LEED) Neighbourhood Development Rating System and the soon-tobe-released Green Building Council of Australia's Green Star for Communities instrument are assisting in this endeavour. Development and implementation of such tools demonstrate an increasing emphasis placed on QoL in approaches to sustainability in the residential sector.

The QoL of a population is an important aspect of economics and political science. These disciplines use metrics to measure both qualitative and quantitative aspects of the phenomenon. QoL studies tend to be macro in scale, covering towns, cities or countries (Wadley, 2010). They attempt to examine dimensions to, and satisfaction regarding, peoples' life style in terms of personal physiological needs, and to what extent they can be met by the local environment. Limitations to these studies have been identified in terms of their lack of holism and connection between outputs and input (Luger, 1996). Luger's research suggests that outcomes of QoL studies might be more attributed to demographic, socio-economic and environmental than economic dimensions. He has argued that these factors are not tracked in a traditional QoL model, a shortfall which makes the studies valueless and antithetical with regard to policy formulation.

A new model of QoL has evolved with a broader focus. It includes both objective indicators of environmental attributes and subjective personal assessment of satisfaction with physical (neighbourhood and facilities), social (relationships and neighbourhood attachment) and economic (financial and employment opportunities) aspects in a neighbourhood (Upadhyay \& Hyde, 2011; Upadhyay, Hyde, \& Wadley, 2010). From this viewpoint, tools can be developed with a range of scales that include the region, city and neighbourhood, and also provide novel methodologies for understanding the relevant phenomena. The holistic model could offer a richer information base to facilitate policy formulation for the planning 
and design of particular aspects of regional infrastructure such as residential neighbourhoods and precincts. However, to provide more quantitative research to test the model, further studies are required: first to examine the relationship between environmental attitudes and community satisfaction; and second to examine that between such attitudes and resource conservation.

The current research project probes the latter issue of resource conservation, utility usage and attitudes within theoretically more sustainable and less sustainable communities, thereby providing an opportunity to better understand QoL perspectives that incorporate environmental factors. It is argued that resource usage and occupant attitudes are best analysed through sampling at a community scale to understand this influence of social factors.

\section{Method}

\section{Research Approach}

The study engaged two communities. The first one featured sustainably designed houses, located in, and occupied by residents of, what is defined for the purposes of this study as The Ecovillage. It can be defined as an "ecologically intentional community", specifically focusing on ecological preservation and other principles of sustainable development. Ecovillage home owners are required to meet comprehensive, developer-inspired Architectural and Landscaping Codes (ALC) which, for example, ban air conditioning (despite being located in a sub-tropical climate region) and mandate solar passive design, making these houses theoretically much more sustainable compared with conventional house designs. These factors, however, could potentially threaten residential satisfaction.

The second community comprises a control group of contemporary houses and their occupants from an estate within the same region and climate zone. It provided a well matched comparison group of conventional homes, of a very similar age to the study group. The control group development applied few restrictions on the building form and, as a result, 
could be deemed a standard and 'ecologically unintentional' community from the ecological and sustainable design points of view. See Table 1 for a summary of design differences between the groups. Key utility consumption data (including water, gas and electricity) were measured from residents' bills and supplemented by data extracted from real time monitoring systems in the Ecovillage houses.

\section{Table 1.}

Characteristics of the Sustainable and Conventional Housing in this Study

\begin{tabular}{|c|c|c|}
\hline Category & Sustainable Housing & Conventional Housing \\
\hline Developer & Strict architectural and landscaping & Minor limitations on design via a \\
\hline Mandated & codes such as no air conditioning, & covenant controlling design features \\
\hline \multirow[t]{4}{*}{ Design } & use of recycled materials, internal & such as carports, external wall finishes, \\
\hline & thermal mass, low toxic paints, & and landscaping; not focused on \\
\hline & energy efficient design, solar passive & sustainable design principles. \\
\hline & design. & No controls on orientation or mass. \\
\hline \multirow[t]{5}{*}{ Energy } & Connected to the local state grid, & Connected to the local state grid, with a \\
\hline & supplemented with solar photovoltaic & small percentage of houses generating \\
\hline & generation on roofs on every house. & solar power on site. \\
\hline & Reticulated underground gas supply & Some use of LPG gas bottles. \\
\hline & (LPG) for heating and cooking. & \\
\hline \multirow[t]{3}{*}{ Water } & Rain water supply only, & Connected to the standard water grid \\
\hline & supplemented with an internal & shared by all other suburbs in the area. \\
\hline & centralised water recycling system. & \\
\hline Shared & Numerous: community hall, & Barbeque facilities, dog walking park, \\
\hline Community & commercial sized kitchen, large & covered outdoor seating and grassed \\
\hline Facilities & pizza oven, 25 meter outdoor pool, & areas. \\
\hline
\end{tabular}


games room, barbeque facilities,

gymnasium, showers, toilets, picnic

tables/facilities, community kitchen,

library, bali huts, artworks, oval and

children's playground.

On the basis of prior studies (Schnieders \& Hermelink, 2006; Szatow, 2011), it was anticipated that sustainably designed residential buildings would demonstrate lower utility usage compared with the control houses. Second, it was predicted that residents with stronger

environmental consciousness (pro-environmental attitudes) would demonstrate lower utility use (Abrahamse, Steg, Vlek, \& Rothengatter, 2005; Balderjahn, 1988). In combination, it was hypothesised that occupants with stronger environmental attitudes and living in sustainably designed houses would achieve the greater relative reduction in utility usage of the two groups. To the authors' knowledge, a study of this depth using such technology and a significant sample size of directly comparable sustainably and conventionally designed dwellings has not previously been undertaken.

\section{Participants and Sample Frame}

A total of 75 participants, one adult per household, were surveyed in regard to environmental attitudes. Utility data was available from 69 of these households, out of a total of 475 eligible houses. The majority (428) of eligible houses were from the control community. Each household was given an equal opportunity to participate. Further information about occupants and household composition appears in the Results section.

The Ecovillage was selected for study because it contained houses that had to comply with prescriptive, sustainable residential building requirements. The control estate, of contemporary housing represented current standard building practice in Australia. Both sites 
were located on the Gold Coast, $100 \mathrm{~km}$ south of the Queensland capital (Brisbane), in a subtropical climate zone.

Eligible householders had built houses on their lots and lived in them for at least six months. Each was mailed an introductory letter inviting participation in the study. An AUD \$50 supermarket voucher was provided to each participating household.

\section{Measurement of Variables}

Utility consumption was measured in two ways. For houses which had a real time monitoring system, consumption of electricity, gas, and water was downloaded, because it provided the most precise information available (Landmatters Currumbin Valley Pty Ltd, 2007). For houses without a utility metering system, energy and water data extracted from paper utility bills were used. For both methods, utility use for at least 3 months was recorded and daily averages were computed.

Occupants also completed surveys to record demographic and dwelling characteristics, and undertook a 36-item version of the Environmental Attitudes Inventory (EAI; Milfont \& Duckitt, 2010). This previously-validated measure has two higher order factors, named Preservation and Utilisation. A Preservation attitude includes enjoyment of nature, support for interventionist conservation policies, environmental movement activism, sense of environmental threat, personal conservation behaviour, ecocentric concern, and support for population growth policies. A Utilisation attitude includes conservation motivated by anthropocentric concern, confidence in science and technology, support for altering nature, support for human dominance over nature, and support for human utilisation of nature. Items are answered on a seven point Likert scale, from $1=$ strongly disagree to $7=$ strongly agree . Excellent internal and test-retest reliability has previously been demonstrated for Preservation and Utilisation for both 72-item and 120-item versions of the EAI. It has been validated crossculturally, shows little effect of social desirability bias, and appears to correlate in predicted 
directions with other environmental attitude indicators (Milfont \& Duckitt, 2010). In the present study, Preservation had a Cronbach's alpha of 0.86 and Utilisation had an alpha value of 0.73

\section{Field Procedures}

Data were collected from March to April 2011. Researchers and trained research assistants visited the houses of people who opted to participate, at a mutually convenient appointment time. Data were gathered in a single session which lasted 50-75 minutes. After providing written informed consent, residents completed paper and pencil surveys. While participants worked on their forms, the researcher recorded data from the utility bills provided. Detailed billing data such as "days of electricity use", amount used, and cost were noted down, so any anomalies in data recording could be identified through cross-checks. An online version of the survey questions was created for those participants who could not meet a university representative in person, but only three participants chose this option. Data from the study group monitoring systems were retrieved by CSV file downloads from a central computer server which automatically collects household utility data.

\section{Statistical Analyses}

All data were placed into spreadsheets and checked before being analysed with the Statistical Package for the Social Sciences (SPSS, version 19). The first set of analyses determined bivariate relationships between potential predictor variables and energy and water use, using t-tests and correlations. The second set used the multivariate technique of hierarchical multiple regression to determine what relationship, if any, sustainable housing design and environmental attitudes had with Utility use, in the presence of other variables that might also affect utility use. In the hierarchical procedure, blocks of predictors are added sequentially to a regression model, rather than entering all predictors simultaneously as in standard multiple regression. At Step 1, design and household characteristics were entered: 
Sustainable Design, size of house, number of occupants, and percent occupied. At Step 2, preservation and utilisation scores were entered to determine whether these environmental attitudes added significantly to variance in utility use after the Step 1 variables had been statistically accounted for. Definitions for the main variables in the study are shown in Table 2.

Table 2.

Variable Definitions

\begin{tabular}{ll}
\hline Variable & Definition \\
\hline Energy & Amount of power used by each dwelling on average per day in kWh \\
& (including electricity and reticulated gas) \\
& Average amount of water consumed per household per day (kL) \\
Water & 0: Dwellings from a conventional (control) subdivision $\quad$ The \\
Sustainably & Observatory) in Reedy Creek QLD (post code 4227) \\
Designed & $\begin{array}{l}\text { 1: Ecovillage (study group) dwellings with post code 4223 which had } \\
\text { to comply with the comprehensive Architectural and Landscaping }\end{array}$ \\
Codes and which claim to be more sustainably designed \\
Preservation (EA)
\end{tabular}




\section{Results}

\section{Initial Data Screening}

Variables were screened to check whether they met the assumptions for parametric analyses. One house within each group had an extremely high value for energy use, that is, more than four standard deviations above the group mean (see Figure 1). On further investigation, the owner of the outlying control house informed researchers that the occupants suspected a fault with their meter and were in a dispute with their energy company about these abnormal readings. The environmentally intentional community owner was grateful to discover that the home's electricity bill was more than twice the average due to a fault with their freezer which was using $5.3 \mathrm{kWh}$ per day. To improve the reliability of analyses, these two outlying houses were excluded from further energy-related analyses. The square root of Energy was used to transform it due to positive skew in its distribution. A reflect and square root transformation was used for the 'percent occupied' variable due to negative skew. 


\section{Figure 1.}

\section{Scatterplot of Energy Consumption by Location}

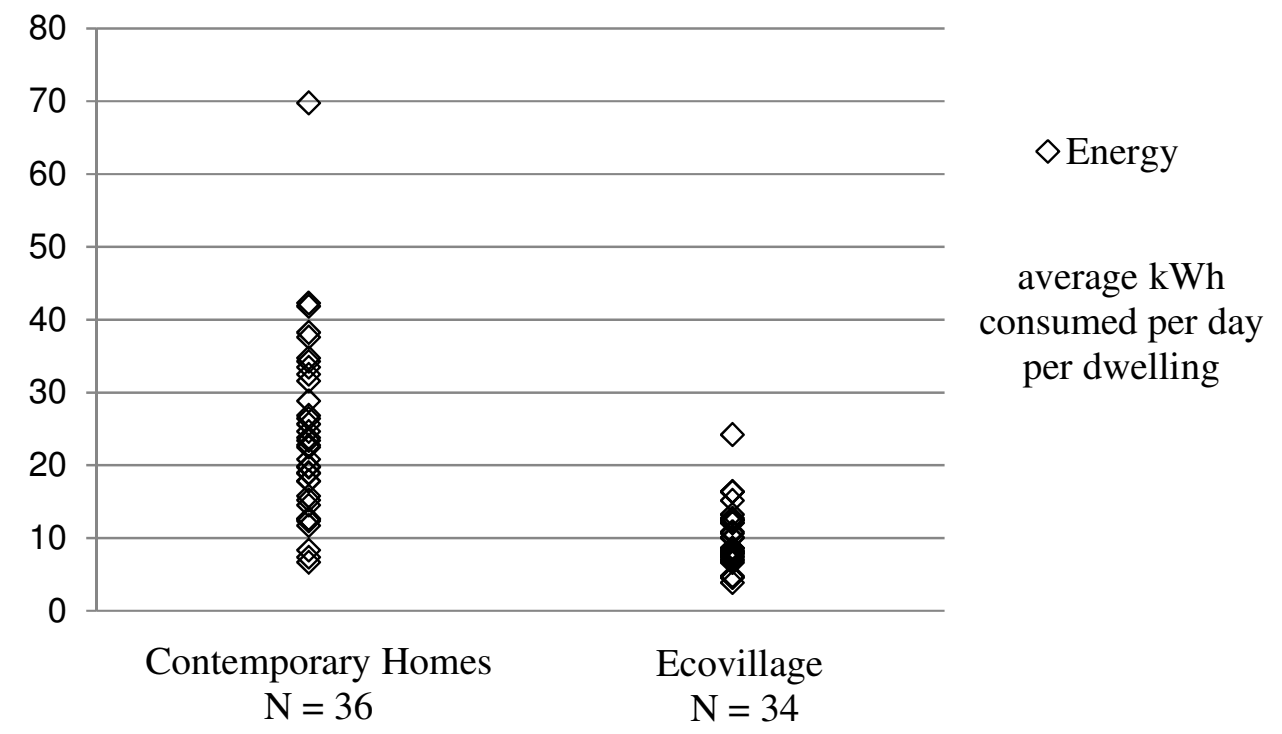

\section{Descriptive Statistics}

Environmental Attitude was collected in two categories, Preservation and Utilisation. Utility Usage was considered in two parts, Energy and Water consumption levels. Energy data were available from the majority of houses that provided survey responses. Water data were not available for some homes so these analyses were based on a smaller number of cases. Descriptive statistics for utility and predictor variables in the two sample locations are shown in Table 3, together with the results from t-tests comparing the estates. An alpha level of 0.05 was used for these comparisons, so t-test values associated with probabilities of $<0.05$ are considered to indicate statistically significant differences between the two groups of houses. 


\section{Table 3.}

\section{Descriptive Statistics for Utility Usage and Key Predictor Variables}

\begin{tabular}{lccccc}
\hline Predictor & Mean (SD) & Mean (SD) & t-test & df & Probability \\
& Observatory & Ecovillage & & & \\
& Control Group & Study Group & & & \\
& $22.76(9.8)$ & $9.65(3.6)$ & 7.587 & 65 & .000 \\
\hline Energy (kWh) & $0.489(0.2)$ & $0.426(0.2)$ & 1.101 & 46 & .277 \\
Water (kL) & $3.4(1.3)$ & $2.6(1.1)$ & 2.833 & 65 & .006 \\
Number of occupants & $328.6(53.4)$ & $194.4(67.2)$ & 9.008 & 64 & .000 \\
Size of house (m $\left.{ }^{2}\right)$ & $80.1(19.0)$ & $79.3(17.9)$ & -0.292 & 65 & .771 \\
Percent occupied & $4.92(0.62)$ & $5.88(0.59)$ & -6.442 & 65 & .000 \\
Preservation & $3.35(0.61)$ & $2.65(0.59)$ & 4.753 & 65 & .000 \\
Utilisation & & & & & \\
\end{tabular}

Note. t-tests for energy and percent occupied used transformed variables but means and standard deviations are presented in raw score form for ease of interpretation. The square root of Energy was used to transform it due to positive skew in Energy. A reflect and square root transformation was used for percent occupied due to negative skew.

In terms of gross energy consumption, the study group houses used $58 \%$ less energy than the control estate (Table 3). The former use reticulated gas for cooking, space heating and hot water boosting and this element was included in the total Energy calculations along with standard grid electricity usage data. The study group used an average of 10 kilowatt hours per household per day $(\mathrm{kWh} / \mathrm{ph} / \mathrm{pd})$ compared with $23 \mathrm{kWh} / \mathrm{ph} / \mathrm{pd}$ for the control group houses (and the State average of $20 \mathrm{kWh} / \mathrm{ph} / \mathrm{pd}$ (Queensland Government, 2011). The difference in energy use between the two groups of houses was statistically significant and is visually presented in Figure 1. The outlying houses in each group are included in Figure 1 but were excluded from statistical analyses, as explained above. Average water usage, per 
household (ph) and per person (pp) was similar in both study group (426 litres per household per day; 164L/pp/pd) and control group homes (489L/ph/pd; 144L/pp/pd) and did not differ significantly between the two groups, as shown in Table 3 .

The number of occupants and size of house were both significantly lower in the study group than in the control group. On average the number of occupants per dwelling was $21 \%$ lower in the study group (2.7 people per night) compared with the control group (3.4). In terms of size (internal rated floor area, which excludes garages), the study group dwellings were significantly smaller $\left(194 \mathrm{~m}^{2}\right)$ than the control group houses $\left(329 \mathrm{~m}^{2}\right)$. The amount of time houses were occupied (Percent Occupied) was comparable (79-80\%) in each community and was found not to differ with any statistical significance between the two groups.

As anticipated, pro-environmental attitudes were significantly higher among participants from the environmentally intentional community than among those from the control group. Preservation scores were significantly higher and Utilisation scores significantly lower among study group than control group residents, as shown in Table 3.

\section{Correlations}

Correlations among the main variables in the study are shown in Table 4. Because Percent Occupied did not differ between the two estates and did not correlate significantly with either energy or water use, it was excluded from further analyses and is not shown in the table. Otherwise, all of the major independent variables correlated significantly with Energy consumption. Only the number of occupants correlated with the amount of water consumed by the house. 


\section{Table 4.}

\section{Correlations Among Major Variables}

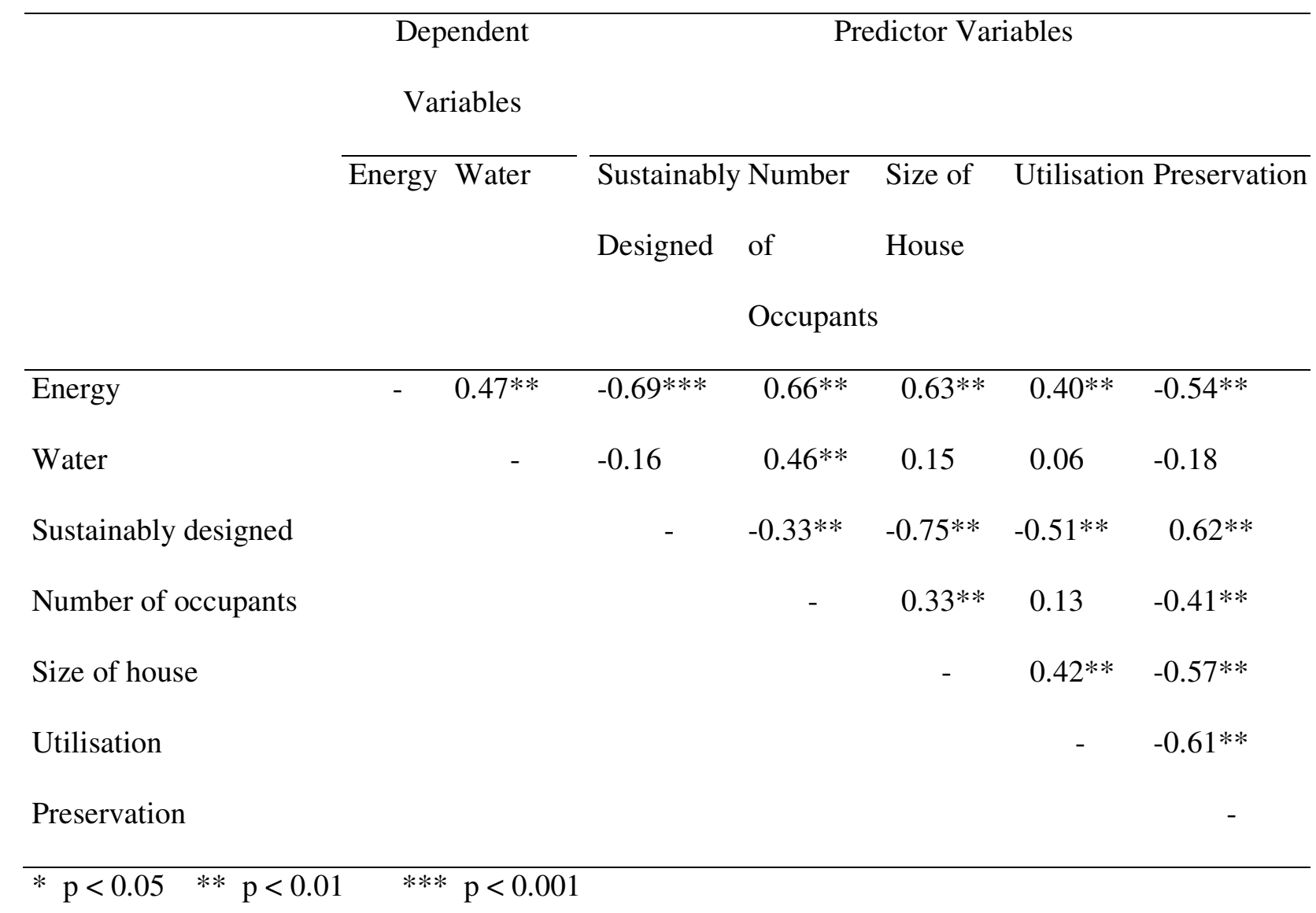

The scatterplot in Figure 2 demonstrates a significant negative correlation between Energy consumption and attitudes favouring environmental preservation, $r=-0.51, p<0.001$. That is, respondents who indicated that they support conservation and protection of the environment typically used less energy in their household. As somewhat expected, the analysis showed that the larger houses typically consumed more energy (see Table 4) with no house less than $200 \mathrm{~m}^{2}$ in area using more than $20 \mathrm{kWh} / \mathrm{ph} / \mathrm{pa}$. Similarly, other correlations in Table 4 were consistent with expectations and with t-test comparisons between the two groups of houses (see Figure 3). 


\section{Figure 2.}

\section{Energy Correlation With Preservation (Environmental Attitude) Responses (N=69)}

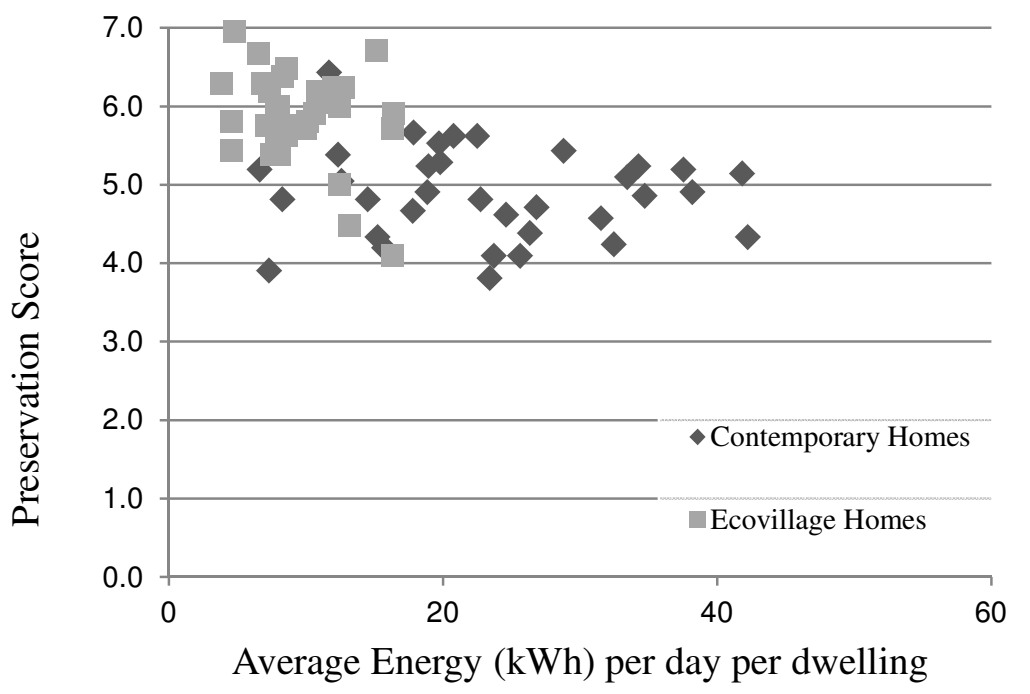

\section{Figure 3}

Plot of Energy Use (kWh) and Dwelling Size $\left(\mathrm{m}^{2}\right)$

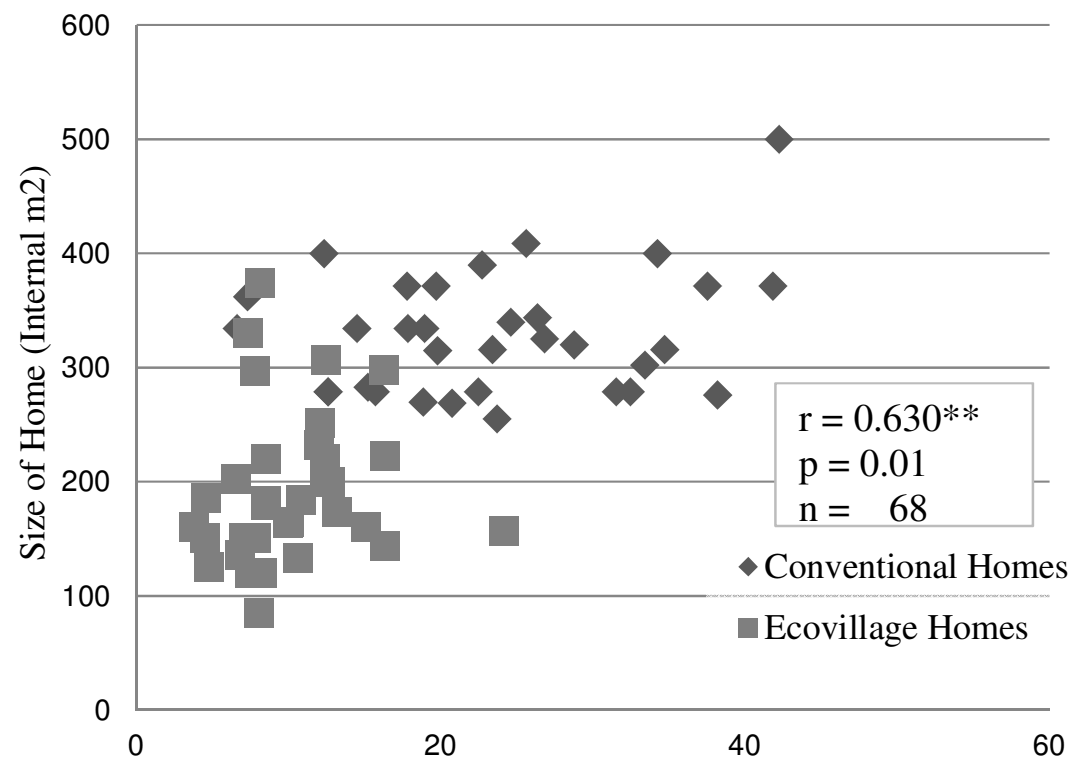

Average Energy (kWh) per day per dwelling 


\section{Multivariate Analysis}

An hierarchical multiple regression was used to evaluate the combined effects of potential predictors of energy consumption. As mentioned, dwelling and demographic characteristics were included first as Step 1. For Step 2, the Environmental attitude variables (Preservation and Utilisation) were included together with all Step 1 variables. Results of the regression are shown in Table 5. Because water use was correlated with only one variable, the number of occupants, a multivariate analysis was not required for this particular element.

\section{Table 5.}

\section{Hierarchical Multiple Regression Analysis For Energy Consumption}

\begin{tabular}{|c|c|c|c|c|c|c|}
\hline \multirow[t]{2}{*}{ Independent Variables } & \multicolumn{3}{|c|}{ Step 1} & \multicolumn{3}{|c|}{ Step 2} \\
\hline & $\mathrm{B}$ & $\beta$ & $\mathrm{sr}^{2}$ & B & $\beta$ & $\mathrm{sr}^{2}$ \\
\hline Sustainably designed & $-1.019 * * *$ & -0.435 & 0.081 & $-0.950 * * *$ & -0.406 & 0.061 \\
\hline Number of occupants & $0.425 * * *$ & 0.455 & 0.180 & $0.440 * * *$ & 0.471 & 0.173 \\
\hline Size of house & 0.002 & 0.154 & 0.010 & 0.002 & 0.152 & 0.010 \\
\hline Utilisation & & & & 0.185 & 0.110 & 0.007 \\
\hline Preservation & & & & 0.073 & 0.048 & 0.001 \\
\hline $\mathrm{R}^{2}$ change & $0.705 * * *$ & & & 0.007 & & \\
\hline F change & $49.293 * * *$ & & & 0.735 & & \\
\hline $\mathrm{R}^{2}$ & $0.705 * * *$ & & & $0.712 * * *$ & & \\
\hline Adjusted R2 & $0.690 * * *$ & & & $0.688 * * *$ & & \\
\hline $\mathrm{F}$ & $49.293 * * *$ & & & $29.617 * * *$ & & \\
\hline
\end{tabular}


In Step 1, house characteristics accounted for a significant amount of variance in energy use: the adjusted $R^{2}$ was 0.690 , indicating that $69 \%$ of variance in energy use was accounted for by the set of predictors. There was a significant beta weight for sustainable design, $\beta=-0.435, p<0.001$, indicating that sustainably designed houses used significantly less energy and that this effect remained significant when other house predictors were taken into account. The squared semi-partial correlation, $\mathrm{sr}^{2}$, indicated that sustainable design uniquely accounted for $8 \%$ of the variance in energy consumption. The number of house occupants was positively related to energy use, $\beta=0.455, p<0.001$, accounting for $18 \%$ of variance. The size of the house accounted for $1 \%$ of the variance in energy use and was not statistically significant $(\beta=0.154, \mathrm{~ns})$.

In Step 2, environmental attitude variables (Preservation and Utilisation) did not add significantly to prediction of energy use, once dwelling characteristics were already accounted for, $\mathrm{R}_{\text {change }}^{2}=0.01$, ns. The overall analysis, including both sets of predictor variables, accounted for $68.8 \%$ of variance in energy use, a level found to be statistically significant, $F$ $(5,61)=29.6, p<.001$. Both sustainable design and number of occupants remained as significant independent predictors of energy used in Step 2. The results suggest that, among the variables included in the present study, a lower number of occupants was the largest independent contributor to reduced energy use, followed by the sustainable design of a house. Although EA (Preservation) scores were significantly correlated with energy use, they did not add further prediction of to this dependent variable when other house characteristics including sustainable design had already been accounted for.

\section{Discussion}

For this study, the primary household resource utilities of energy and water consumption were investigated at two comparable residential estates. The impact of major variables such as (sustainable) house design, size of house, hours occupied and the number of 
occupants was analysed from an examination of consumption data and questionnaire results. The results highlight the importance of passive design to operational performance of the built environment. With or without other variables controlled, the dwellings within the study group were found to consume significantly less energy. The hierarchical multiple regression results suggest that, after accounting for other key variables such as the number of occupants and size of houses, the difference was primarily due to the sustainable design of the homes rather than to environmental attitudes of residents.

Analysis of the data suggests the sustainable design of a home contributes significantly to reducing its energy use. In the case of the study group, which contains homes that must meet comprehensive sustainable design criteria, average energy use was $58 \%$ less than that of the comparable control group when not taking into account the power generated by households. Each study group home is required to install a minimum of $1 \mathrm{~kW}$ of solar photovoltaic panels and, on average, the cells generated $4.1 \mathrm{kWh}$ per day. Some residents with $1.5 \mathrm{~kW}$ or $2 \mathrm{~kW}$ solar energy systems were able to ensure that more energy was created than they used, triggering their electricity companies to pay them for the power, rather than having to pay any electricity bills themselves. When taking into account the power generated, the study group homes used just $5.7 \mathrm{kWh}$ of grid power per day on average. This figure was $75 \%$ lower than the net energy use of the control group houses, which consumed energy at an average rate of $23 \mathrm{kWh}$ per day.

The number of people in each house also correlated positively with the amount of energy consumed, as expected. The size of a house did correlate with energy use, but when included in a model with other variables more strongly associated with energy use, it did not have a statistically significant independent association. These effects are important to note, because both the size of houses and number of people per house were greater in the control group. However, when multivariate regression testing included these variables, the sustainable 
design of the house was still found to be an independent contributor to the variance in the model.

The reduced energy use is likely to be attributable to key features in each of the study group houses, including their use of exclusively solar-based hot water systems, insulation exceeding minimum Building Code of Australia standards, higher specification "low-e" glazing, eaves the optimal length to keep the sun out in summer and allow it inside in winter, limited west-facing thermal mass, protected internal thermal mass, efficient lighting and a dark sky policy to minimise lighting consumption and pollution. This result was achieved even though each study group house uses a water pump for potable water movement (transfer of rain water to each bathroom/kitchen outlet within the house). Note also that 23 control group houses had swimming pools and they regularly use pool pumps, which are a known high energy demand appliance. The study group shared one common pool facility.

It is acknowledged that only operational energy was studied. The embodied energy of the houses, all less than 5 years old on both estates, would need to be included in any full lifecycle assessment analysis.

In terms of water, both estates used a similar amount. This consumption was not found to differ significantly in relation to the design of houses or other factors apart from the number of occupants. It is observed, however, that the study group has its own internal water cycle and management system, which takes no town supply, whereas the control group uses primarily town water (489 litres/ph/pd). To evaluate the full lifecycle cost, the price of supplying water should be considered, as previously studied by Kenway et al (2008). The differing results for water and energy show that different utilities and operational impacts need to be considered separately, because they can differ in the factors that influence them.

Those who reported that they were in favour of environmental preservation tended to consume less energy, implying their attitudes and values impacted their behaviour, and 
specifically, their energy-related household operations: for example turning lights off; closing blinds and curtains on hot days; eliminating standby appliance power; and activity using natural ventilation and fans instead of air conditioning. Further correlations between Environmental Attitudes and utility consumption conducted separately within each estate showed no statistically significant correlations, but there was a trend towards a correlation within the study group $, r=-0.306, p=0.088$. It suggests that residents in a sustainably designed house with higher pro-preservation attitudes can contribute to their homes' using even less energy. This trend was not seen in the control group responses, perhaps because the reduced level of sustainable design in those houses restrains residents who have higher environmental preservation attitudes from being able to reduce their energy consumption. For example, houses designed without reference to the local climate and passive solar considerations could retain excessive heat at night in summer, requiring the use of mechanical air conditioning to maintain an acceptable indoor temperature. Alternatively, this trend could be explained by residents' having different priorities such as financial or comfort interests or differing levels of knowledge about what saves power. That is to say, a home owner might prefer environmentally friendly options and aim to reduce his or her energy use, but only after other priorities have been met, such as having a pool, a large television or more appliances to provide more lifestyle options.

Typically, a lower level of energy and water consumption might be associated with a lower quality of life. In contrast, the residents in the environmentally intentional community still share a high quality of life (Upadhyay \& Hyde, 2011) and all have the basic services. Most have the same appliances and luxuries one would associate with a high standard of living. Large televisions, baths, internet, computers and barbeques are common in both study locations. It therefore appears possible to enjoy high living standards without consuming as much energy as the current average Queensland household. 
There were a number of strengths of this study. Both the sustainably designed and comparison estates were in the same area, which allowed climate and other potential differences to be held constant. In the geographical sciences, studies have demonstrated the role that space and place play in consumption (Goss, 2006; Mansvelt, 2009; Perkins, Hamnett, Pullen, Zito, \& Trebilcock, 2009). Real time data from study group houses supplemented meter and billing data from the control houses and allowed extraneous data to be identified and potentially removed to enhance the accuracy of the investigation. For example, if a gas meter had a leak, gas data for the specific house during the period between leak detection and its subsequent rectification could be omitted from the house's average energy use, whereas billing data from utility providers did not allow for such interrogation. Collection of a range of personal data allowed adjustment for various physical and demographic characteristics. The inclusion of multiple types of information permitted utility data to be correlated with surveys of attitude from the same sample used to measure the impact of sustainable design. This approach differed from that of other studies, which have characteristically focused only on consumption data or attitude.

Limitations are also noted. The sample size was reasonably small so this constrained the statistical power of the study. However, similar enquiries combining utility use and attitudes in comparing sustainably and non-sustainably designed houses do not appear to have been attempted before. It would also be practically very difficult to survey any larger number of "sustainable" houses in Queensland, given that they are widely distributed around the State. There are relatively few such homes and their ages differ widely.

\section{Conclusion}

This project looked into the relation of housing design, occupant attitudes and resultant energy use in two varying residential situations. As a key outcome, results failed to demonstrate that environmentally favourable attitudes contributed significantly to lower 
energy use, when other house design factors had already been taken into account. However, people interested in preserving the environment tended to use less energy when considering just these two variables. Given that a squared correlation can indicate the amount of overlap in variance that is shared by two variables, it can be seen that the sustainably designed houses were associated with $34 \%$ of the variance in energy consumption per household whereas the two environmental attitude variables were associated with only $14 \%$ and $20 \%$ of the variability in energy. From the particular study sites chosen, this finding suggests that the sustainable design of a house is twice as likely to reduce a house's energy consumption compared with the influence of environmental attitudes.

The results further suggest that utility consumption is a key factor, which should be considered in models evaluating the economic, social and environmental aspects that affect QoL. The determinants of utility consumption were found to be the number of occupants and the sustainable design of the dwelling, with environmental attitudes having less influence. The sustainable design results suggest that the building form is a crucial factor, which is likely to influence residential QoL. Furthermore QoL which included ecological factors could provide a good predictor for liveability and residential wellbeing in a sustainable context.

Further research is needed to support the set of indicators used to underpin the QoL model. Additional studies that would extend this project include exploration of transport and appliance use as indicators. Studies of transportation could estimate the energy required to carry people and goods to and from the houses, and would provide an additional view on the aggregate residential sustainability by incorporating dwelling density and location perspectives. Another recommended enquiry would involve recording the quantities, types and usage of household appliances within houses, to enable direct comparison with previous data (Newton \& Meyer, 2011). Embodied energy from dwelling construction would also be included in more comprehensive models of environmental impact. 


\section{Acknowledgements}

The overall research project is managed by the University of Sydney in conjunction with the University of Queensland and funded by the Australian Research Council (ARC Linkage Grant ID LP0774952 CI Name: Hyde, R and Wadley, D). Study partners included Landmatters Pty Ltd, Department of Natural Resources, EcoVision and Gold Coast City Council (Gold Coast Water). PhD candidate Anir Upadhyay assisted throughout the study, and continues to extend the research by combining it with neighbourhood satisfaction results. The study was possible only with the cooperation of the residents of The Ecovillage at Currumbin, and the Observatory in Southeast Queensland, Australia, who kindly gave their

time to complete the surveys. We are also indebted to research assistants Collette Morris and Sam Pforr. The project is approved under The University of Sydney Ethics Protocol. 


\section{References}

Abrahamse, W., Steg, L., Vlek, C., \& Rothengatter, T. (2005). A review of intervention studies aimed at household energy conservation. Journal of Environmental Psychology, 25, 273-291.

Australian Bureau of Statistics. (2008). Environmental issues: energy use and conservation. 4602.0.55.001.

Balderjahn, I. (1988). Personality variables and environmental attitudes as predictors of ecologically responsible consumption patterns. Journal of Business Research, 17, 51-56.

Fishbein, M., \& Ajzen, I. (1972). Attitudes and opinions. Annual Review of Psychology, 23, 67.

Goss, J. (2006). Geographies of consumption. Progress in Human Geography, 30, 12.

Grafton, R. Q. (2009). Determinants of residential water demand in OECD countries. Paper presented at the OECD Conference on Household Behaviour and Environmental Policy. Retrieved 3 Nov 2011, from http://www.oecd.org/dataoecd/41/62/43181240.pdf

Hines, J., Hungerforda, H., \& Tomerab, A. (1987). Analysis and synthesis of research on responsible environmental behavior: A meta-analysis. The Journal of Environmental Education, 18, 1-8.

Holden, E. (2004a). Ecological footprints and sustainable urban form. Journal of Housing and the Built Environment, 19, 18.

Holden, E. (2004b). Towards sustainable consumption: do green households have smaller

ecological footprints? International Journal on Sustainable Development, 7, 14.

Holden, E., \& Linnerud, K. (2010). Environmental attitudes and household consumption: an ambiguous relationship. International Journal of Sustainable Development, 13, 15.

Hyde, R. A., Moore, R., Kavanagh, L., Watt, M., Prasad, D., \& Blair, J. (2005). Development of a planning and design tool for assessing the sustainability of precincts. Paper presented at the 39th Annual Conference of the Australian and New Zealand Architectural Science Association (ANZASCA), Victoria University, Wellington, New Zealand.

Hyde, R. A., \& Rostvik, H. (2008). Redefining bioclimatic housing. In R. Hyde (Ed.), Bioclimatic housing: innovative designs for warm climates (pp. 22-36). Trowbridge, UK: Earthscan/James \& James.

Intergovernmental Panel on Climate Change IPCC. (2007). 4th Assessment Report

Kaiser, Wölfing, \& Fuhler. (1999). Environmental attitude and ecological behaviour. Journal of Environmental Psychology, 19, 1-19.

Kenway, S. J., Priestley, A., Cook, S., Seo, S., Inman, M., Gregory, A., et al. (2008). Energy use in the provision and consumption of urban water in Australia and New Zealand. Water Services Association of Australia.

Landmatters Currumbin Valley Pty Ltd. (2007). Architectural and landscaping codes. 1, 76.

Lavik, R. (1997). Miljøengasjement i endring, Arbeidsrapport nr. Oslo: Statens institutt for forbruksforskning.

Luger, M. I. (1996). Quality of life differences and urban and regional outcomes: A review. Housing Policy Debate, 7, 749-771.

Manfred, L., Christopher, D., \& Barney, F. (2004). Energy requirements of Sydney households. Ecological Economics, 49, 375-399.

Mansvelt, J. (2009). Geographies of consumption: the unmanageable consumer? Progress in Human Geography, 33, 10.

Martimportugués, C., Canto, J. M., García, M. A., \& Hidalgo, C. (2002). Actitudes hacia el ahorro de agua: Un análisis descriptivo. Medio Ambiente y Comportamiento Humano, 3, 119-143.

Mawhinney, M. (2002). Sustainable development: understanding the green debates. Oxford: WileyBlackwell.

Milfont, T. L., \& Duckitt, J. (2006). Preservation and utilization: understanding the structure of environmental attitudes. Medio Ambiente y Comportamiento Humano, 7, 29-50.

Milfont, T. L., \& Duckitt, J. (2010). The environmental attitudes inventory: a valid and reliable measure to assess the structure of environmental attitudes. Journal of Environmental Psychology, 30, 80-94. 
Newton, W. P., \& Meyer, D. (2011). Who cares? An exploration of attitudes and behaviour. In Newton (Ed.), Urban Consumptionism (pp. 267-291). Melbourne: CSIRO.

Perkins, A., Hamnett, S., Pullen, S., Zito, R., \& Trebilcock, D. (2009). Transport, housing and urban form: the life cycle energy consumption and emissions of city centre apartments compared with suburban dwellings. Urban Policy and Research, 27, 19.

Queensland Government. (2010). Designing for Queensland's Climate. Brisbane: Queensland Government.

Queensland Government. (2011). Toward Q2: tomorrow's Queensland. Brisbane, Australia.

Schnieders, J., \& Hermelink, A. (2006). CEPHEUS results: measurements and occupants satisfaction provide evidence for Passive Houses being an option for sustainable building. Energy Policy, 34, 151-171.

Szatow, A. (2011). Cape Paterson Ecovillage: Zero Carbon Study Peer Review. Melbourne: Victorian Government.

Troy, P., Holloway, D., \& Randolph, B. (2005). Water use and the built environment: patterns of water consumption in Sydney. Sydney: University of New South Wales.

United Nations. (1986). Our Common Future, Chapter 2: Towards Sustainable Development. UN Report of the World Commission on Environment and Development A/42/427.

Upadhyay, A., \& Hyde, R. A. (2011). Does sustainable housing contribute to a better Quality of Life to the residents? A study of the Ecovillage at Currumbin. Paper presented at the 12th APRU Doctoral Students Conference (APRU DSC), Tsinghua University, Beijing, China. Retrieved 12 January, 2012, from http://apru.daf.tsinghua.edu.cn/

Upadhyay, A., Hyde, R. A., \& Wadley, D. (2010). Towards a new paradigm for the assessment of sustainable housing- a quality of life approach. Paper presented at the ANZAScA 2010, Auckland New Zealand.

Wadley, D. (2010). Exploring a quality of life, self-determined. Architectural Science Review, 53, 1220.

Wandersman, A. H., \& Hallman, W. K. (1993). Are people acting irrationally? Understanding public concerns about environmental threats. American Psychologist, 48, 681-686. 